\title{
FIN 48: The Impact On Staffing, Internal Control Processes And Expertise Of Privately-Held Companies
}

\author{
Reed C. Kirschling, Tax Consultant, Deloitte Tax LLP
} Michael D. Akers, Marquette University

\begin{abstract}
While FASB Interpretation 48 (FIN 48), Accounting for Uncertainty in Income Taxes-An Interpretation of Statement of Financial Accounting Standards (SFAS) 109, Accounting for Income Taxes applies to both privately-held and publicly traded companies, privately-held companies have characteristics that can impact implementation. This paper reports the findings of a survey of the top 100 privately-held companies to determine how these organizations are addressing the staffing of tax department personnel, process controls and knowledge acquisition during the implementation of FIN 48.
\end{abstract}

Keywords: FIN 48-staffing, controls, expertise

\section{INTRODUCTION}

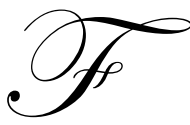

ASB Interpretation 48 (FIN 48), Accounting for Uncertainty in Income Taxes-An Interpretation of Statement of Financial Accounting Standards (SFAS) 109, Accounting for Income Taxes, was implemented to reduce the diversity among the methods that various companies employed to assess their tax positions when reporting financial statements. FIN 48, issued in June 2006 by the FASB, became effective for financial statements issued after December 15, 2006.

To assess the viability of uncertain tax positions, FIN 48 requires a two-step process. First, the taxpayer must determine whether the tax position will initially be recognized. This requires the taxpayer to determine whether it is more likely than not that the tax position will be sustained on an audit. Secondly, the taxpayer must determine the amount that is more likely than not to be recognized. Determining whether a tax position will more likely than not be recognized on an audit and the amount the taxpayer should recognize are complicated issues with which many companies are not currently ready to address. Consequently, companies are being forced to consult more with outside help or increasing their tax department staff internally.

While there has been much discussion of the impact of FIN 48 on public companies in the media, there has been very little discussion of how privately-held companies how are reacting with respect to staffing of tax department personnel, process controls and methods to obtain the appropriate level of expertise to handle the technical issues of FIN 48. The purpose of this paper is to examine, using the findings of a survey, how privatelyheld companies plan to address these issues. As noted by Smith (2007) privately-held companies have four characteristics that create specific challenges. First, the size of privately-held companies might preclude them from having sufficient tax personnel. Second, private companies are not required to follow SOX. Accordingly, privately-held companies that have not implemented the appropriate internal controls or sufficiently documented those controls may have a harder time complying with FIN 48. Third, private companies might have had less interaction with the Internal Revenue Service. This potentially becomes a problem in determining the amount to be recognized in an uncertain tax position. Accordingly, these smaller companies will be forced to consult with tax firms or other experienced people in the industry to help them determine the correct amount to be reported under 
FIN 48. Fourth, privately-held companies might take more aggressive tax positions since shareholders are more concerned with tax savings than earnings.

To determine how privately-held companies are addressing staffing issues, process controls and the appropriate level of knowledge in order to comply with FIN 48, we developed a short one-page survey (Appendix A), which was mailed to the Controllers of the 100 largest private companies in the United States In developing the survey we talked with a Tax Manager at a Big 4 Accounting Firm to determine a practitioner's perspective of the issues with the implementation of FIN 48. The Tax Manager provided critical insight, which helped us focus the survey on issues with which companies are facing in the early stages of implementation. The preliminary survey draft was examined by a Tax Director of another Big 4 Accounting firm. Minor changes were made to the survey to incorporate her suggestions. Her feedback also affirmed that the survey addressed the significant issues associated with the implementation of FIN 48. The first section of the paper examines the design of the survey followed by the analysis of the findings and concluding comments.

\section{STUDY}

\section{Survey Design}

The survey was designed to examine how FIN 48 was affecting the professional staff, resources, and tax positions of privately held companies. Specifically, the survey focused on the areas of staffing, process, information, and content. The questions in the staffing area of the survey focused on whether private companies would increase the head count of their tax departments to better handle the requirements of FIN 48, and also the amount of experience that each company desired when expanding the tax department headcount. We also asked the controllers as to whether they intended to outsource the work necessary to comply with the Fin 48 requirements as compared to expansion of the tax department. The process area focused on two areas: tax technology improvements and tax department process improvements. The objective of these questions was to determine how private companies were improving their departments, both in process and in technology, in order to comply with FIN 48. In the information area the objectives were to learn whether private companies were adequately informed of FIN 48 , the sources by which they became informed, and whether the private companies more frequently consulted with their auditors or outside tax consultants regarding the FIN 48 requirements. Lastly, the content area focused on the tax areas that private companies felt FIN 48 would most likely impact. Additionally, we wanted to determine whether privately held companies believe the "more-likely-than-not" threshold of FIN 48 will decrease the tax benefits recognized.

\section{Results}

Our response rate of $38 \%$ is very good for a mail survey which suggests that the controllers are interested in this topic. This is consistent with the attention that Fin 48 has received in business press and professional publications.

\section{Staffing}

Our findings indicate that the respondents plan to rely more on the use outside tax consultants as compared to increasing the size of their tax department. Only five respondents (13\%) plan to hire new employees in the Tax Department within the next twelve months while approximately half (47\%) of the respondents plan to hire outside tax consultants.

Of the respondents who said they planned to hire new employees, the required level of experience (limited1 to 3 years; moderate- 3 to 9 years; experienced-more than 9 years) was evenly spread among the three categories of experience. A few of the respondents said they planned to hire additional staff, but not within the next twelve months. 


\section{Process}

Thirty percent $(30 \%)$ of the respondents plan to undertake tax department process improvements to help address the additional burdens imposed by FIN 48. Those processes include an increased level of internal controls, more non-United States education for its current employees, a greater number of employees attending foreign seminars, greater involvement in the international tax area, and better linkage between its assets' book and tax values. Forty-six percent (46\%) of the respondents are going to implement tax technology improvements including Fin 48 software, such as Tax Stream, and more modern depreciation software.

Although privately-held companies are not required to the follow the requirements of SOX many privatelyheld companies and nonprofit organizations have enhanced internal controls and the related documentation as a result of SOX. This might explain the low percentage of our respondents that cited process or technology improvements. We expected more companies would be involved in process or technology improvements for two reasons. First, a recent article (JOA June 2007) regarding SOX, section 404 reporting, noted the most frequent GAAP failure related to tax expense/benefit/deferral/FAS 109 issues. Second, the AICPA Practice Guide on Accounting for Uncertain Tax Positions Under FIN 48 clearly states that one of the implications for financial statement preparers is adequate documentation supporting tax positions for tax returns and financial statements.

\section{Information}

The majority $(89 \%)$ of the respondents believe their tax department has been adequately informed of the requirements of FIN 48. Respondents indicated the following sources were used to obtain a better understanding of Fin 48: accounting firms (cited by 26 respondents), seminars (22), internal research (21), audit firm (17), and other companies (6).

Most (76\%) of the respondents have also increased their consultation with their outside auditors or tax consultants regarding the implementation of FIN 48. This finding is consistent with an "immediate action item (consult outside auditors and tax advisors to coordinate FIN 48 analysis)" cited by the AICPA in the Practice Guide on Accounting for Uncertain Tax Positions Under FIN 48 issued November 29, 2006. While external auditors can provide consultation services to the tax department of privately held companies regarding FIN 48, as long as the auditors do not act in the capacity of management, the external auditors of public companies are prohibited from providing such services by Sarbanes-Oxley. Accordingly, audit firms continue to be a source of valuable tax advice for privately held companies, who do not fall within the purview of SOX.

\section{Content}

Approximately half (54\%) of the respondents do not believe the "more-likely-than-not" threshold will decrease their tax benefits while $24 \%$ are unsure and $22 \%$ agree that tax benefits will decrease. These findings illustrate the uncertainty of the impact of FIN 48 as companies analyze the effect on their uncertain tax positions.

Regarding the area of taxation where FIN 48 will create the most concern, the respondents indicated federal taxes (cited by 25 respondents) is the area of greatest concern followed by state and local taxes (11) and international taxes (11). While we were not surprised that by the areas of concern cited by the respondents, we were surprised that federal taxes were cited more than twice the number of times as the other two areas. This finding is consistent with Smith's (2007) suggestion that privately-held companies might have less interaction with the Internal Revenue Service than public companies and therefore, federal taxation is an area of concern when implementing FIN 48. One survey respondent noted, "the most difficulty with FIN 48 is determining the 'ultimate' amount expected to be settled with the IRS on an uncertain issue. Many smaller companies that are not in a regular audit cycle in IRS LMSB division may not have experience with unagreed [sic] issues." Radin (2007) provides an excellent explanation as to why state and local taxes are also an area of major concern. 


\section{CONCLUSION}

While there has been considerable discussion about the potential impact of FIN 48 there has been limited research as how entities, specifically privately-held companies, are reacting to this interpretation. To gain a better understanding as to how these organizations are implementing FIN 48, we surveyed the controllers of the 100 largest privately-held companies. Our findings show these companies are soliciting input from their outside auditors, other accounting firms, seminars as well as conducting internal research in order to obtain a sufficient understanding of the requirements of FIN 48. While most of the firms do not expect to increase the size of their tax department, the majority of the firms do plan to increase the utilization of outside tax consultants, which is good news for firms that provide tax consultation services. Consistent with the AICPA recommendation in the practice for FIN 48, our results show that approximately $75 \%$ of the respondents are more frequently consulting with their external auditors and tax advisors.

The respondents of this study consider federal taxes to be the greatest area of concern followed by international and state and local taxes. Although the majority of the respondents don't believe the "more-likely-thannot" threshold will decrease tax benefits, approximately $25 \%$ of the respondents were unsure which suggests a certain level of uncertainty. Considering the problems encountered by public companies with internal controls related to the tax area we were surprised to find that less than half the respondents plan are planning for process improvements in the tax department or improvements with tax technology. It is possible that these companies are still evaluating the best way to meet the requirements of FIN 48. Future research should continue to examine this issue.

\section{REFERENCES}

1. American Institute of Certified Public Accountants (AICPA). 2006. Practice Guide on Accounting for Uncertain Tax Positions Under FIN 48.

2. Radin, Arthur. 2007. Uncertainties Created by FIN 48, Accounting for Uncertainty in Income Taxes. The CPA Journal. (April): 9-11.

3. Smith, Thacher. 2007. FIN 48: Best Practices for Private Companies. www.complianceweek.com (June): 26-28. 


\section{APPENDIX A \\ Fin 48 Survey}

Please respond to the following questions relating to the effect Fin 48 will likely have, as well as the effects already felt by your company.

1. We plan to change the head count or tax department structure within the next 12 months.

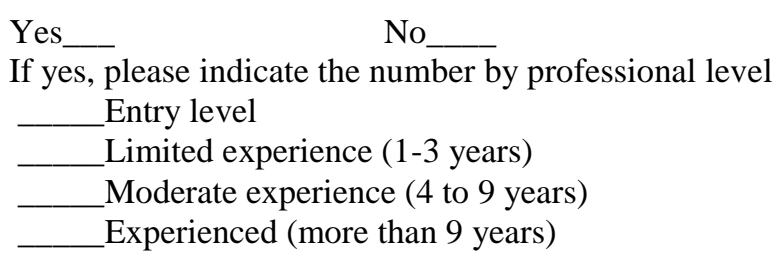

2. We plan to undertake tax department process improvements within the next 12 months.

$$
\text { Yes_ yes, please indicate what type of improvements }
$$

3. The "more likely than not" threshold has greatly decreased tax benefits as compared to prior years.

$$
\text { Strongly Agree } \quad \text { Agree } \quad \text { No Opinion } \quad \text { Disagree } \quad \text { Strongly Disagree }
$$

4. We plan to undertake tax technology improvements, including software implementation and process automation.

$$
\begin{aligned}
& \text { Yes_ } \\
& \text { If yes, please indicate what type of improvements }
\end{aligned}
$$

5. We plan to increase training to deal with the additional burden on the tax department.

$$
\text { Yes__ No_ }
$$

6. We more frequently consult with outside auditors and tax advisors.

$$
\text { Strongly Agree } \quad \text { Agree } \quad \text { No Opinion } \quad \text { Disagree } \quad \text { Strongly Disagree }
$$

7. We will more likely hire outside tax consultants as compared to increasing our internal tax department. .

$$
\text { Strongly Agree } \quad \text { Agree No Opinion Disagree } \quad \text { Strongly Disagree }
$$

8. What is the greatest challenge in identifying the company's uncertain tax positions and then estimating the transition amounts? 
NOTES 